\title{
Synthesis of iron/GAC catalyst for wastewater treatment using heterogeneous Fenton reaction
}

\author{
S T T LE ${ }^{1,2}$, T T NGO ${ }^{3}$, W KHANITCHAIDECHA ${ }^{1,2}$ and A NAKARUK ${ }^{4,5, *}$ \\ ${ }^{1}$ Department of Civil Engineering, Faculty of Engineering, Naresuan University, Phitsanulok, Thailand \\ ${ }^{2}$ Centre of Excellence for Innovation and Technology for Water Treatment, Naresuan University, Phitsanulok, Thailand \\ ${ }^{3}$ Department of Environmental Technology, Faculty of Environmental Science, University of Science, Viet Nam National \\ University, Ho Chi Minh City, Viet Nam \\ ${ }^{4}$ Department of Industrial Engineering, Faculty of Engineering, Naresuan University, Phitsanulok, Thailand \\ ${ }^{5}$ Center of Excellence for Environmental Health and Toxicology, Naresuan University, Phitsanulok, Thailand
}

MS received 16 September 2014; accepted 3 February 2015

\begin{abstract}
Iron catalyst dispersed on granular activated carbon (GAC) was prepared by impregnating $\mathrm{Fe}\left(\mathrm{NO}_{3}\right)_{3}$ solution on GAC. The mixed solution was annealed at $600^{\circ} \mathrm{C}$ in muffle furnace under ambient condition for $1 \mathrm{~h}$. The structural property of the catalyst was investigated using X-ray diffraction (XRD). The catalyst's activity and lifetime were tested using the degradation of $50 \mathrm{ppm}$ methyl orange (MO) solution. In addition, the optimum conditions of the Fenton reaction such as initial $\mathrm{pH}$, initial MO concentration hydrogen peroxide concentration and the amount of catalyst were also investigated. The XRD results showed that magnetite and haematite were two main compositions of the synthesized catalyst. The investigation of optimum conditions suggested that initial pH at 3 provided the highest efficiency of MO removal. In addition, the concentration of hydrogen peroxide at 8 ppm was the most suitable. The optimum condition of amount of catalyst was $5 \mathrm{~g} \mathrm{l}^{-1}$. The efficiencies of MO removal reached $95 \%$ at 60 min of reaction time at low initial MO concentration $\left(25-500 \mathrm{mg} \mathrm{l}^{-1}\right)$. In the meantime, the removal efficiency was found to decrease with the increase in the initial MO concentration. The efficiency decreased to 70 and $30 \%$ at 1000 and $3000 \mathrm{mg} \mathrm{l}^{-1}$ of initial MO concentration, respectively. Additionally, after reuse the synthesized catalyst 3 times the MO removal efficiency still remained over $90 \%$. In conclusion, the iron/GAC catalyst was successfully synthesized and applied to dye treatment using heterogeneous Fenton reaction. The catalyst showed high efficiency of MO removal and could be reused many times.
\end{abstract}

Keywords. Fenton reaction; iron oxide; activated carbon; methyl orange.

\section{Introduction}

At present, wastewater treatment is one of the most important issues in underdeveloped countries due to increasing contamination in water and the shortage of proper wastewater treatment technologies. There are several technologies that are widely used for wastewater treatment such as adsorption, filtration, chemical process and membrane technologies. Above-mentioned techniques are considered as effective technologies to remove toxic pollutants. However, these processes simply transfer pollutants to other phases that cannot completely eliminate. Also, some chemical processes can generate secondary products or intermediate phases that are highly toxic than the primary pollutants. ${ }^{1,2}$ In order to overcome the mentioned problems, advanced oxidation processes (AOPs) have been introduced. Briefly, mechanism of AOPs is the generation of hydroxyl radical $\mathrm{OH}^{\bullet}$ that is a highly reactive and non-selective oxidant. Thus, it can mineralize a variety of organic contaminants. ${ }^{3,4}$ Among the present AOPs,

\footnotetext{
*Author for correspondence (auppathamn@nu.ac.th)
}

homogeneous Fenton reaction is one of the most promising techniques because of its low cost and non-toxic. ${ }^{5,6}$

The principle of homogeneous Fenton reaction is to generate hydroxyl radical $\mathrm{OH}^{\bullet}$ via the reaction between ferrous ion and hydrogen peroxide ${ }^{1,2}$

$$
\begin{aligned}
& \mathrm{Fe}^{2+}+\mathrm{H}_{2} \mathrm{O}_{2} \rightarrow \mathrm{Fe}^{3+}+\mathrm{HO}^{\bullet}+\mathrm{OH}^{-}, \\
& \mathrm{Fe}^{3+}+\mathrm{H}_{2} \mathrm{O}_{2} \rightarrow \mathrm{Fe}^{2+}+\mathrm{HO}_{2}^{\bullet}+\mathrm{H}^{+} .
\end{aligned}
$$

When organic pollutants are present in the system, the generated hydroxyl radicals $\mathrm{OH}^{\bullet}$ react with the organic molecules to form the simpler and readily biodegradable products, or even carbon dioxide and water in theory

$$
\mathrm{HO}^{\bullet}+\mathrm{R}-\mathrm{H} \rightarrow \mathrm{CO}_{2}+\mathrm{H}_{2} \mathrm{O} .
$$

However, there is a limitation that is the formation of iron sludge. ${ }^{7,8}$ Therefore, the use of heterogeneous Fenton reaction has been proposed in order to solve the sludge problem. Fenton reaction using heterogeneous catalysts such as nano-sized iron particles and iron dispersed on a carrier have been reported in many literature reviews. ${ }^{9,10}$ The generation of hydroxyl radical $\mathrm{OH}^{\bullet}$ via the reaction between iron 
particles on the catalyst's surface and hydrogen peroxide has been proposed as follows: ${ }^{8}$

$$
\begin{aligned}
& \mathrm{Fe}(\mathrm{II})_{\text {surf }}+\mathrm{H}_{2} \mathrm{O}_{2} \rightarrow \mathrm{Fe}(\mathrm{III})_{\text {surf }}+\mathrm{HO}^{\bullet}+\mathrm{HO}^{-}, \\
& \mathrm{Fe}(\mathrm{III})_{\text {surf }}+\mathrm{H}_{2} \mathrm{O}_{2} \rightarrow \mathrm{Fe}(\mathrm{III})_{\text {surf }}\left(\mathrm{H}_{2} \mathrm{O}_{2}\right), \\
& \mathrm{Fe}(\mathrm{III})_{\text {surf }}\left(\mathrm{H}_{2} \mathrm{O}_{2}\right) \rightarrow \mathrm{Fe}(\mathrm{II})_{\text {surf }}+\mathrm{HO}_{2}^{\bullet}+\mathrm{H}^{+} .
\end{aligned}
$$

Concerning about iron dispersed on a carrier, there are various kinds of porous materials which can be used as carriers. Among which, granular activated carbon (GAC) is a promising material due to its low cost, availability, porous structure and high specific surface area. ${ }^{11}$ Thus, the intention of the present work was to synthesize a heterogeneous Fenton catalyst by dispersing iron oxides on GAC and evaluate organic pollutant removal efficiency.

\section{Experimental}

GAC produced from coconut shells was used as raw materials to synthesize the catalyst. In order to enhance the adsorption of metallic ions on GAC, ${ }^{12,13}$ GAC sized from 1 to $2 \mathrm{~mm}$ was modified by soaking GAC in $20 \%$ of $\mathrm{HNO}_{3}$ solution at $65^{\circ} \mathrm{C}$ for $4 \mathrm{~h}$. Later, GAC was washed with deionized water and dried overnight. Briefly, $10 \mathrm{~g}$ of modified GAC was then impregnated with $36 \mathrm{ml}$ of $1 \mathrm{M} \mathrm{Fe}\left(\mathrm{NO}_{3}\right)_{3} \cdot 9 \mathrm{H}_{2} \mathrm{O}$ solution at $65^{\circ} \mathrm{C}$ for $4 \mathrm{~h}$. Afterwards, the mixture was dried at $105^{\circ} \mathrm{C}$ for $2 \mathrm{~h}$ and then annealed in a muffle furnace under ambient conditions at $600^{\circ} \mathrm{C}$ for $1 \mathrm{~h}$, followed by natural cooling. Later, the annealed particles that is called Fe/GAC catalyst were stored for use.

The structural characteristics of the synthesized catalyst were examined using X-ray diffraction (XRD, $0^{\circ}-80^{\circ} 2 \theta$, speed $0.02^{\circ} 2 \theta \mathrm{s}^{-1}$, step $0.01^{\circ} 2 \theta$ step). The catalyst's activity was tested using batch experiment with methyl orange (MO) solution. In a typical experiment, Fe/GAC catalyst was placed into a $100 \mathrm{ml}$ Erlenmeyer flask containing $50 \mathrm{ml}$ of $50 \mathrm{mg} \mathrm{l}^{-1} \mathrm{MO}$ solution. Later, $30 \%$ of hydrogen peroxide solution was added into the Erlenmeyer flask. The mixture was mixed by a shaker at $150 \mathrm{rpm}$ for $60 \mathrm{~min}$. Finally, the catalyst was removed from the solution by vacuum filter. The efficiency of MO removal was obtained by measuring the absorbance intensity of $\mathrm{MO}$ at $\lambda_{\max }=465 \mathrm{~nm}$ for $\mathrm{pH} \leq 3$ and at $\lambda_{\max }=500 \mathrm{~nm}$ for $\mathrm{pH}>3 .^{6}$ The effects of initial $\mathrm{pH}$, initial MO concentration, hydrogen peroxide concentration and the amount of catalyst were also investigated. In addition, the reusable ability of Fe/GAC catalyst was tested by washing the used catalyst with deionised water, and then drying at $105^{\circ} \mathrm{C}$. The catalyst was reused following the same above procedure.

\section{Results and discussion}

Figure 1 shows the XRD pattern of the synthesized Fe/GAC catalyst. The XRD result presents that the catalyst consisted of two phase of iron oxide: magnetite $\left(\mathrm{Fe}_{3} \mathrm{O}_{4}\right)$ and haematite $\left(\mathrm{Fe}_{2} \mathrm{O}_{3}\right)$. The former is major phase and the latter

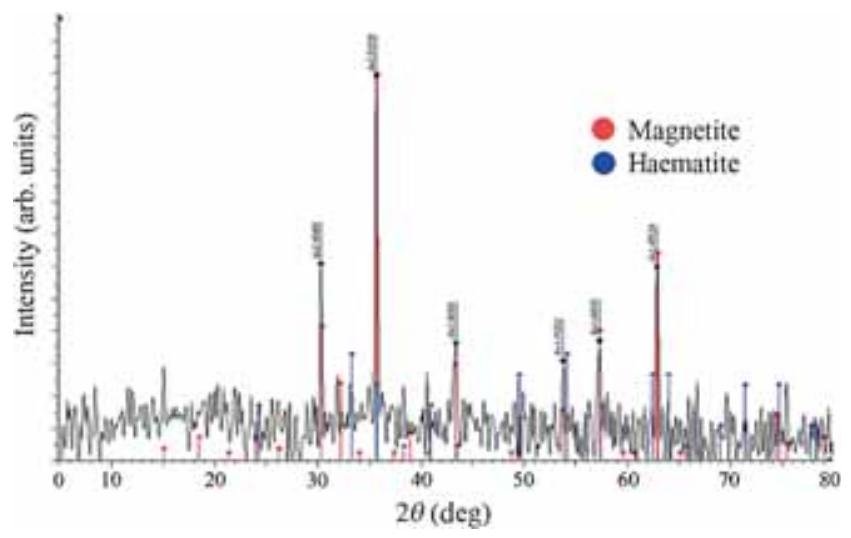

Figure 1. XRD pattern of the synthesized Fe/GAC catalyst.

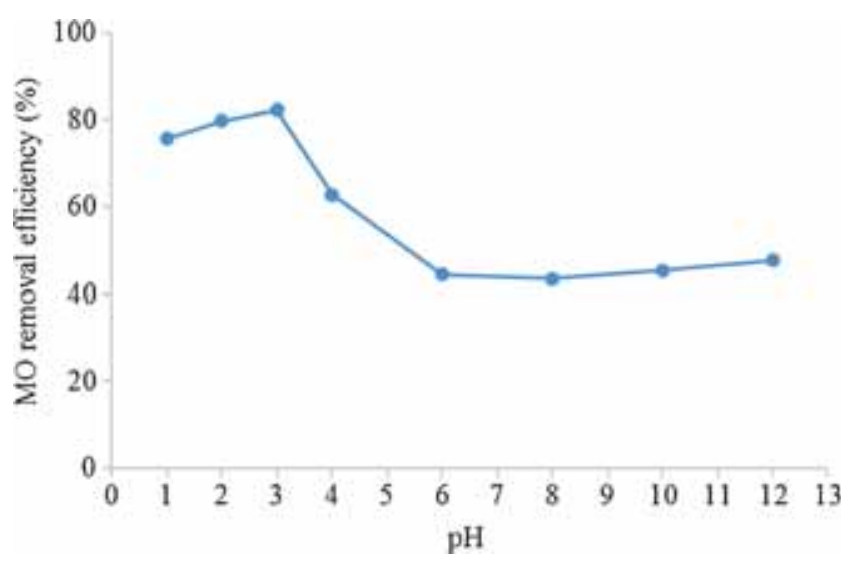

Figure 2. Effect of initial $\mathrm{pH}$ of $\mathrm{MO}$ solution on $\mathrm{MO}$ removal efficiency $\left(m_{\text {catalyst }}=4 \mathrm{~g} \mathrm{l}^{-1},\left[\mathrm{H}_{2} \mathrm{O}_{2}\right]=4 \mathrm{mg} \mathrm{l}^{-1},[\mathrm{MO}]_{\text {initial }}=\right.$ $\left.50 \mathrm{mg} \mathrm{l}^{-1}, t=60 \mathrm{~min}\right)$.

is minor phase. The possible explanation of the presence of two phases of iron oxide is that the oxygen diffusion into particles is limited to only at the surface of particles. Although, the catalyst was synthesized under ambient condition, magnetite can occur because of the low rate of oxygen diffusion. It has to be noted that the catalyst particles were annealed in a crucible in a relatively short period ( $1 \mathrm{~h}$ of annealing time), oxygen could not diffuse deep into the particles at the bottom of the crucible. This means only the particles on the top of the crucible were exposed to enough oxygen to form haematite while the beneath particles under the low oxygen condition transformed to magnetite. The difference in the colour of the particles can also prove this explanation. The particles on the top have reddish brown colour as haematite while the beneath particles are brownish black like magnetite.

Figure 2 shows the effect of initial $\mathrm{pH}$ of $\mathrm{MO}$ solution on MO removal efficiency. It can be seen that MO removal efficiency decreased with increasing of $\mathrm{pH}$ from 3 to 8 . This is because at higher $\mathrm{pH}$, the hydrolysis process of iron ions is dominant. ${ }^{14}$ This means the precipitated iron hydroxides are formed and deposited on the surface of catalyst. This phenomenon can inhibit the electron transfer between iron and hydrogen peroxide. Therefore, the hydroxyl radical 
generation is limited, leading to the decrease of MO removal efficiency. On the other hand, MO removal efficiencies at $\mathrm{pH}$ of 1 and 2 were slightly lower than that at $\mathrm{pH}$ of 3 . This is due to the excess hydrogen ion at low $\mathrm{pH}$ acting as a hydroxyl radical consumer. ${ }^{14}$ In this case, at $\mathrm{pH}$ of 1 and 2 , there are too much hydrogen ions in the medium, which compete with MO to react with hydroxyl radical, resulting in the low efficiency.

In addition, the variation of MO removal efficiency at different initial $\mathrm{pH}$ values might be influenced by the change of the surface charge in respect of initial $\mathrm{pH}$. It can be seen that the synthesized Fe/GAC catalyst had the ability to absorb MO molecules, which contributed to the total MO removal efficiency. This observation has been proved by the experiment of MO removal in the absence of hydrogen peroxide, which is shown in figure 3. It is well known that the adsorption process can be affected by the surface charge of the adsorbent. ${ }^{15}$ As presented in table 1, the point of zero charge of Fe/GAC catalyst was 7.25. Therefore, at low $\mathrm{pH}$ values, catalyst's surface present positive charge, which may enhance the adsorption of $\mathrm{MO}$ anions $\left(\mathrm{C}_{14} \mathrm{H}_{14} \mathrm{~N}_{3} \mathrm{SO}_{3}^{-}\right)$. In contrast, at higher $\mathrm{pH}$, the negative charge on the surface of the catalyst may resist to absorb the MO anions. In comparison, the point of zero charge of haematite, magnetite and

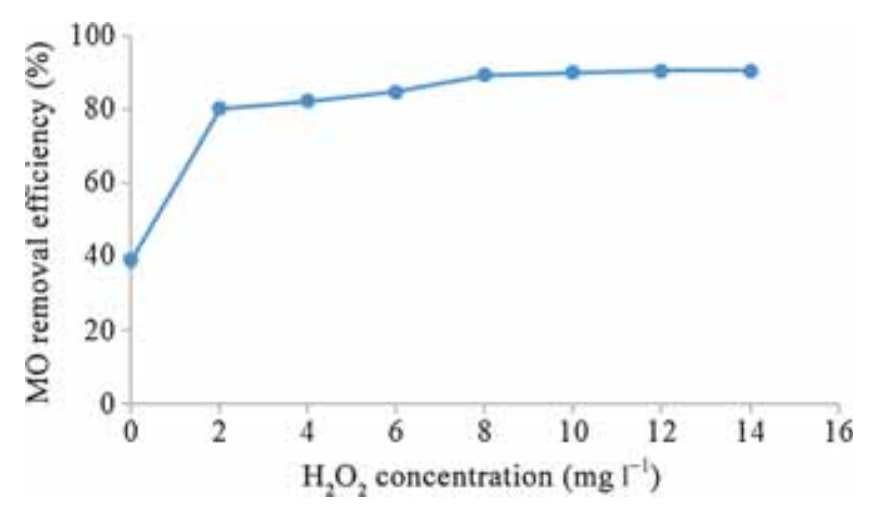

Figure 3. Effect of hydrogen peroxide concentration on $\mathrm{MO}$ removal efficiency $\left(m_{\text {catalyst }}=4 \mathrm{~g} \mathrm{l}^{-1},[\mathrm{MO}]_{\text {initial }}=50 \mathrm{mg} \mathrm{l}^{-1}\right.$, $t=60 \min , \mathrm{pH}=3$ ).

Table 1. The point of zero charge (PZC) of the synthesized catalyst and its MO removal efficiency at different initial $\mathrm{pH}$ values of MO solution.

\begin{tabular}{|c|c|c|c|c|}
\hline No. & Sample & $\begin{array}{l}\text { pHPZC of } \\
\text { sample }\end{array}$ & $\begin{array}{l}\text { Initial } \mathrm{pH} \\
\text { of solution }\end{array}$ & $\begin{array}{l}\text { MO removal } \\
\text { efficiency }(\%)\end{array}$ \\
\hline 1 & Modified GAC & 8.12 & 3 & 60 \\
\hline 2 & $\mathrm{Fe} / \mathrm{GAC}$ & 7.25 & 1 & 75.65 \\
\hline 3 & $\mathrm{Fe} / \mathrm{GAC}$ & 7.25 & 2 & 79.7 \\
\hline 4 & $\mathrm{Fe} / \mathrm{GAC}$ & 7.25 & 3 & 82.16 \\
\hline 5 & $\mathrm{Fe} / \mathrm{GAC}$ & 7.25 & 4 & 62.61 \\
\hline 6 & $\mathrm{Fe} / \mathrm{GAC}$ & 7.25 & 6 & 44.31 \\
\hline 7 & $\mathrm{Fe} / \mathrm{GAC}$ & 7.25 & 8 & 43.35 \\
\hline 8 & $\mathrm{Fe} / \mathrm{GAC}$ & 7.25 & 10 & 45.19 \\
\hline 9 & $\mathrm{Fe} / \mathrm{GAC}$ & 7.25 & 12 & 47.55 \\
\hline
\end{tabular}

modified GAC was found to be $7.3,{ }^{16} 6.5^{17}$ and 8.1 (table 1), respectively. Meanwhile, the point of zero charge of Fe/GAC catalyst was 7.25.

Figure 3 shows the effect of hydrogen peroxide concentration on MO removal efficiency. It can be seen that about $40 \%$ of MO is removed in the absence of hydrogen peroxide due to the MO adsorption of Fe/GAC catalyst, as shown in figure 3. At $2 \mathrm{mg} \mathrm{l}^{-1}$ of hydrogen peroxide, the MO removal efficiency increases significantly to $80 \%$ and then reaches the peak of $90 \%$ at $8 \mathrm{mg} \mathrm{l}^{-1}$ of hydrogen peroxide.

The MO removal efficiency increases with the increasing amount of Fe/GAC catalyst and reaches the peak of $94 \%$ at $5 \mathrm{~g} \mathrm{l}^{-1}$, as shown in figure 4 . Both the catalyst and hydrogen peroxide are the hydroxyl radical generators. Therefore, when the amount of the catalyst and hydrogen peroxide increase, the hydroxyl radical generation also increases, leading to the higher MO removal efficiency. However, Fe(II) content in the catalyst also plays a role as a hydroxyl radical consumer. $^{8}$ As a result, when the amount of Fe/GAC catalyst exceeds $5 \mathrm{~g} \mathrm{l}^{-1}$, the content of $\mathrm{Fe}$ (II) is relatively high and starts to compete with MO on consuming hydroxyl radical, leading to the stable MO removal efficiency. In addition, it has to be noted that in the absence of Fe/GAC and only hydrogen peroxide in the solution cannot remove MO.

Figure 5 presents the effect of initial MO concentration on the MO removal efficiency. It can be said that MO can be removed effectively ( $>80 \%$ of removal) in the range of 25-500 $\mathrm{mg} \mathrm{l}^{-1}$. However, when the initial MO concentration increases up to $3000 \mathrm{mg}^{-1}$, the efficiency decreases dramatically to $\sim 30 \%$.

Figure 6 shows the lifetime of Fe/GAC catalyst. When reusing $\mathrm{Fe} / \mathrm{GAC}$ catalyst for three times, the MO removal efficiency slightly decreases from 95 to $88 \%$. Afterwards, the MO removal efficiency decreases dramatically. This is because the active sites on the catalyst are covered by the adsorbed MO molecules while these adsorbed MO molecules cannot be desorbed by only washing and heating at $105^{\circ} \mathrm{C}$. Therefore, the hydroxyl radical generation is limited, leading to the decrease of efficiency. These results proved that

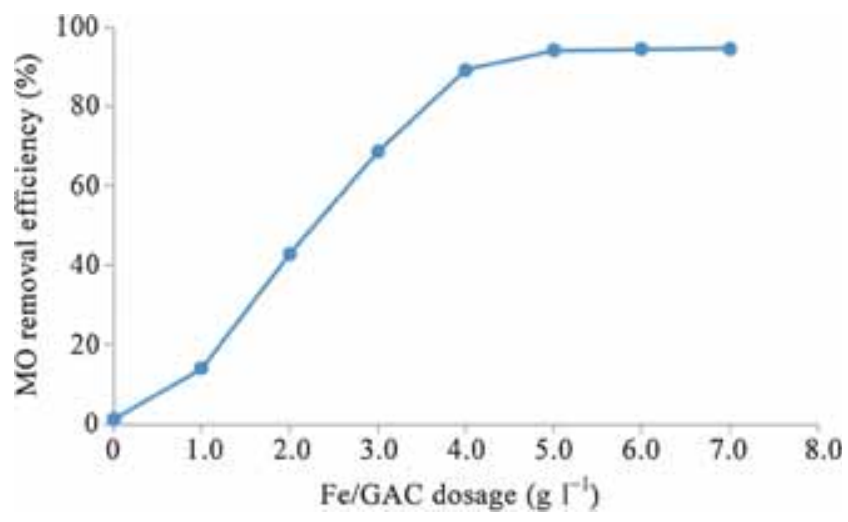

Figure 4. Effect of the amount of catalyst on MO removal efficiency $\left(\left[\mathrm{H}_{2} \mathrm{O}_{2}\right]=8 \mathrm{mg} \mathrm{l}^{-1},[\mathrm{MO}]_{\text {initial }}=50 \mathrm{mg} \mathrm{l}^{-1}, t=60 \mathrm{~min}\right.$, $\mathrm{pH}=3)$. 


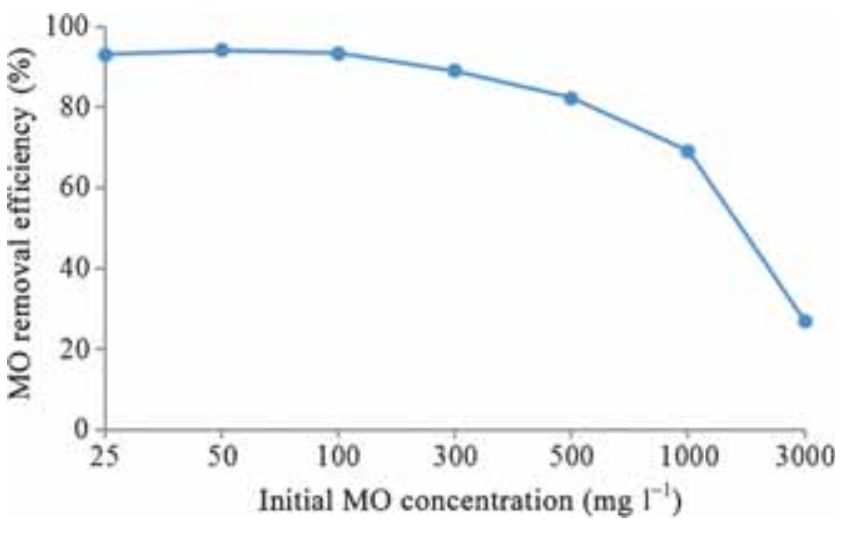

Figure 5. Effect of initial MO concentration on MO removal efficiency $\left(m_{\text {catalyst }}=5 \mathrm{~g} \mathrm{l}^{-1},\left[\mathrm{H}_{2} \mathrm{O}_{2}\right]=8 \mathrm{mg} \mathrm{l}^{-1}, t=60 \mathrm{~min}\right.$, $\mathrm{pH}=3)$.

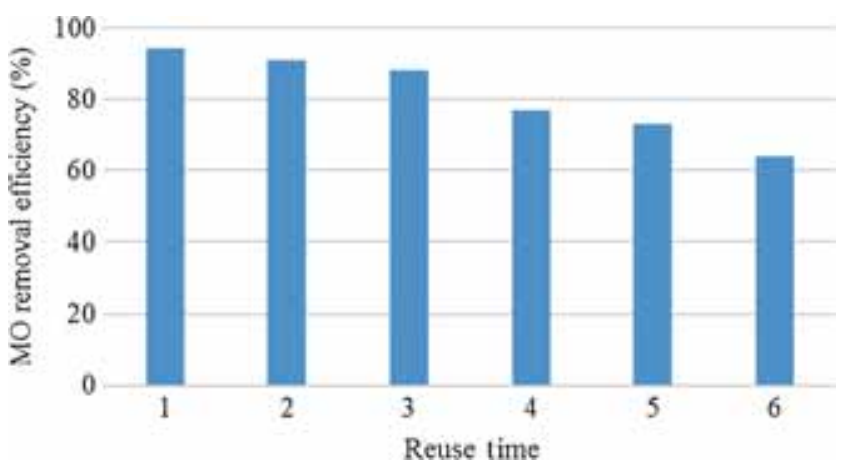

Figure 6. MO removal efficiency using reused catalyst $\left(m_{\text {catalyst }}=5 \mathrm{~g} \mathrm{l}^{-1},\left[\mathrm{H}_{2} \mathrm{O}_{2}\right]=8 \mathrm{mg} \mathrm{l}^{-1},[\mathrm{MO}]_{\text {initial }}=50 \mathrm{mg} \mathrm{l}^{-1}\right.$, $t=60 \min , \mathrm{pH}=3$ ).

the synthesized $\mathrm{Fe} / \mathrm{GAC}$ catalyst is relatively stable and can be reused many times. However, the MO removal efficiency after reusing it for 6 times still remains over $60 \%$.

\section{Conclusions}

In this work, iron oxides dispersed on GAC catalyst was successfully synthesized by impregnating $\mathrm{Fe}\left(\mathrm{NO}_{3}\right)_{3}$ solution on GAC and then annealing the mixture at $600^{\circ} \mathrm{C}$ for $1 \mathrm{~h}$. The structural characteristics of the synthesized catalyst was examined using XRD. The catalyst's activity and lifetime were tested using $50 \mathrm{mg} \mathrm{l}^{-1}$ of MO solution. The XRD results showed that there were two iron oxides phases in the catalyst. They were magnetite and haematite due to the limited oxygen diffusion in the catalyst during annealing process. The results of MO removal test suggested that the highest efficiency was achieved at initial $\mathrm{pH}$ of 3 . Meanwhile, the optimum dosage of hydrogen peroxide and $\mathrm{Fe} / \mathrm{GAC}$ were found to be $8 \mathrm{mg} \mathrm{l}^{-1}$ and $5 \mathrm{~g} \mathrm{l}^{-1}$, respectively. In addition, the $\mathrm{MO}$ removal reaction obtained the highest efficiencies at low initial MO concentration (25-500 $\mathrm{mg}^{-1}$ ). Furthermore, the catalyst reuse test proved that the synthesized catalyst could be reused for many times with a simple regeneration method that is to wash with water and then dry at $105^{\circ} \mathrm{C}$. In conclusion, the $\mathrm{Fe} / \mathrm{GAC}$ catalyst was found to be a promising material for wastewater treatment.

\section{Acknowledgements}

We would like to thank Opa Tangpitukkul's scholarship and Naresuan University's research funding for the financial support.

\section{References}

1. Bokare A D and Choi W 2014 J. Hazard. Mater. 275121

2. Ramirez J H, Maldonado-Hódar F J, Pérez-Cadenas A F, Moreno-Castilla C, Costa C A and Madeira L M 2007 Appl. Catal. B: Environ. 75312

3. Basturk E and Karatas M 2014 Ultrason. Sonochem. 211881

4. Manenti D R, Módenes A N, Soares P A, Espinoza-Quiñones F R, Boaventura R A R, Bergamasco R and Vilar V J P 2014 Chem. Eng. J. 252120

5. Babuponnusami A and Muthukumar K 2014 J. Environ. Eng. 2557

6. Nguyen T D, Phan N H, Do M H and Ngo K T 2011 J. Hazard. Mater. 185653

7. Duartea F, Maldonado-Hódar F J and Madeira L M 2011 Appl. Catal. B: Environ. 103109

8. Rusevova K, Kopinke F and Geogri 2012 J. Hazard. Mater. 241-242 433

9. Merayo N, Hermosilla D, Cortijo L and Blanco Á $2014 J$. Hazard. Mater. 268102

10. Soon A N and Hameed B H 2011 Desalination 2691

11. Bach A and Semiat R 2011 Desalination 27357

12. Bhatnagar A, Hogland W, Marques M and Sillanpää M 2013 Chem. Eng. J. 219499

13. Rivera-Utrilla J, Sánchez-Polo M, Gómez-Serrano V, Álvarezc P M, Alvim-Ferraz M C M and Dias J M 2011 J. Hazard. Mater. 1871

14. Shimizu A, Tokumura M, Nakajima K and Kawase Y 2012 J. Hazard. Mater. 201-202 60

15. Xi Y, Megharaj M and Naidu R 2011 Appl. Clay. Sci. 53716

16. Plaza R C, Gonzalez-Caballero F and Delgado A V 2001 Colloid Polym. Sci. 2791206

17. Milonjic S K, Kopecni M M and Elic Z E 1983 J. Radioanal. Chem. 7815 